\title{
Report of a pre ICN workshop on Negotiating the Future of Nutrition, Johannesburg, South Africa, 18 September 2005
}

Good nutrition underpins good health. That reality has been shown in repeated studies and quantified most recently in the 2002 World Health Report of the World Health Organization (WHO) ${ }^{1}$. In that report, food and nutrition (their lack or over-consumption) accounted for considerable mortality and morbidity worldwide. Despite the compelling evidence of need, global action remains inadequate. Nutrition and food policy still receives considerably less attention in health policy and funding arenas than do many other lesser contributors to human health. Part of the reason relates to the lack of a strong coordinated voice for the broad area that is inclusive of all committed to and able to influence policies and actions for populations.

To stimulate constructive debate about how best to move ahead, the organisers of the 18th International Congress on Nutrition (ICN) convened a one-day meeting of major stakeholders. They included representatives of the food and advertising industries, international nongovernmental organisations (NGOs), United Nations (UN) agencies and leading academics.

The fact of the meeting itself was felt to be significant. Groups who should meet openly and transparently and have not, found common ground on many issues. An overriding theme for the day was how to define win-win solutions. The meeting contributed to a better understanding of the unique and complementary roles of different groups, and to specific suggestions as to how to work better together in the future. The discussions were not meant to lead merely to platitudes and vague support for policies. Rather the aim was to assess critically why progress has been so slow; to identify how key stakeholders may have retarded progress; and to identify ways to move ahead. The first step was to agree that there was a problem that required innovative solutions, that required all involved to move beyond their existing positions to identify potential win-win solutions. The meeting was guided by experience from the negotiation of democratic change in South Africa leading up to the 1994 general elections.

The day began with reflections from stakeholder groups as to why nutrition has not been higher on the political agenda, and why we (all those working or involved in nutrition) have not been more successful in addressing such important problems. UN agencies had been good in developing ambitious recommendations without having the resources and power to implement a fraction of them; although the food industry is investing more and more in healthier products and even consumer education, many food companies had been slow in acknowledging their role in contributing to obesity and in not doing more to address hunger; and NGOs had been strong on critique (especially of food companies) and weak on useful advice. Further, there was an acknowledgement that academia had compartmentalised the broad field into those working on undernutrition, overnutrition, specific ingredients and agricultural policy without adequately developing an integrated approach that straddled all these areas. In this area at least, the International Union of Nutritional Sciences (IUNS) has taken the lead in a project aimed at redefining and broadening nutrition science and practice to include biological, social and environmental dimensions in an attempt to address nutritional problems in a sustainable way that will balance the health of humans and of the biosphere ${ }^{2,3}$.

This self-critique was used as the basis for looking forward. It was agreed that a broader vision for nutrition policy was essential. And that it should embrace those active in trying to reduce the 850 million people who are hungry and underweight, the two billion people who are micronutrient-deficient, the one billion people who are overweight or obese, those who lack access to adequate fruit, vegetables, grains and beans, and the many involved in finding ways to do so in a way that is sustainable, pro-health and profitable. This will be challenging to achieve. It was agreed that one solution will not fit all problems, but that a more coherent, integrated and internationally appropriate approach that meshed together was required.

\section{The way forward}

Several ideas for how to move ahead were considered. Some required more debate; others more research and many required action.

First, additional debate is needed about the optimal balance achievable between government policies, individual and corporate actions. It was widely agreed that all those involved had to play their roles better: that for healthy choices to be truly easy and sustainable for the poorest and least educated in society (those at greater risk and in whom the burden of poor nutrition is greatest), stronger emphasis needed to be given to policy and environmental interventions. A more holistic approach was required that addresses the basic and 
underlying causes needed to balance consumer awareness/knowledge as the key constraint in a model for action. Lessons from successes in other public health areas support this. Further, there was a need to avoid simplifying the issues and portraying them as questions of regulating or self-regulating. Some degree of government regulation was needed to ensure that progressive companies operated on a level playing field with competitors who refused to shift their policies on marketing to children or the salt, sugar or fat content of their products. There was less clarity as to what role, and how, companies could/should engage in, and support, solutions to global problems of undernutrition.

Second, more research is needed to understand what constitutes the optimal mix of policies that would reduce obesity and undernutrition levels in different societies. It was noted in the meeting that there was no best practice to guide countries - but there were important clues from consumer behaviour research, economics and other areas of public health that could guide the immediate development of policies.

The group agreed that those involved in the governance of food, nutrition and related policies needed to develop policies together that were coherent and acknowledged the strengths of each player. If nutrition problems are to be addressed, let alone solved, all of the key stakeholders - academic, food companies, government officials, NGOs - must be involved to the greatest extent possible, although effective ways to exercise this involvement remain to be determined. Only by doing this would nutrition receive the higher profile it deserves in public health debates about funding and action. The question remains: who will take the lead to ensure that emotive talk and lofty words, debate and research will be translated into concrete actions that will indeed make a difference?

\section{Participants}

Professor Derek Yach (Facilitator), Dr Theuns Eloff (Facilitator), Professor Barrie Margetts (Rapporteur), Professor HH (Esté) Vorster (Rapporteur), Professor Mark Wahlqvist (IUNS Council), Professor Ibrahim Elmadfa (IUNS Council), Professor Phillip James (Civil Society), Professor Marion Nestle (Civil Society), Dr Francesco Branca (WHO), Dr Brian Thompson (Food and Agriculture Organization), Dr Ian Darnton-Hill (United Nations Children's Fund), Ms Judy van Dam (Advertising), Ms Jane Lyne (Advertising), Dr Niels Christiansen (Nestlé), Mr John Ruff (Kraft), Dr Paulus Verschuren (Unilever), Dr JeanMichel Antoine (Danone) and Ms Giséle Fournier (Danone).

D Yach

School of Medicine

Department of Epidemiology and Public Health

Yale University, New Haven, CT, USA

T Eloff and HH Vorster

North-West University (Potchefstroom Campus)

Potchefstroom, South Africa

BM Margetts

Public Health Nutrition

Institute of Human Nutrition

University of Southampton, Southampton, UK

\section{References}

1 World Health Organization. 2002 World Health Report Reducing Risks, Promoting Healthy Life [online]. Available at http://www.who.int/whr/2002/en

2 Cannon G, Leitzmann C. The new nutrition science project. Public Health Nutrition 2005; 8(6A): 673-94.

3 McMichael AJ. Integrating nutrition with ecology: balancing the health of humans and biosphere. Public Health Nutrition 2005; 8(6A): 706-15. 